\title{
Chapter 6 \\ Expression and Functions of SARS Coronavirus Replicative Proteins
}

\author{
Rachel Ulferts, Isabelle Imbert, Bruno Canard, and John Ziebuhr
}

\begin{abstract}
The discovery of a previously unknown coronavirus as the causative agent of the SARS epidemic in 2002/2003 stimulated a large number of studies into the molecular biology of SARS coronavirus (SARS-CoV) and related viruses. This research has provided significant new insight into the functions and activities of the coronavirus replicase-transcriptase complex, a multiprotein complex that directs coordinated processes of both continuous and discontinuous RNA synthesis to replicate and transcribe the large coronavirus genome, a single-stranded, positivesense RNA of $\sim 30 \mathrm{~kb}$. In this chapter, we review our current understanding of the expression and functions of key replicative enzymes, such as RNA polymerases, helicase, ribonucleases, ribose-2'-O-methyltransferase and other replicase geneencoded proteins involved in genome expression, virus-host interactions and other processes. Collectively, these recent studies reveal fascinating details of an enzymatic machinery that, in the RNA virus world, is unparalleled in terms of the number and nature of virally encoded activities involved in virus replication and host interactions.
\end{abstract}

\subsection{Introduction}

Coronaviruses and their closest relatives from the order Nidovirales have exceptionally large RNA genomes of about $30 \mathrm{~kb}$ and synthesize an extensive set of 5'-leader-containing, subgenome-length RNAs. The synthesis of these RNAs is mediated by the viral replicase-transcriptase complex (RTC), a large multisubunit complex that is comprised of more than a dozen proteins encoded by the viral replicase gene and other proteins. The RTC includes the key replicative proteins of

\footnotetext{
J. Ziebuhr $(\bowtie)$

Centre for Infection and Immunity, School of Medicine, Dentistry and Biomedical Sciences, The Queen's University of Belfast, Belfast, United Kingdom e-mail: j.ziebuhr@qub.ac.uk
} 
the virus, such as RNA-dependent RNA polymerase (RdRp) and helicase activities, as well as enzymes that are thought to be involved in the processing and modification of viral and/or cellular RNAs, such as primase, endoribonuclease, exoribonuclease and ribose- $2^{\prime}-O$-methyltransferase activities (for recent reviews, see Masters 2006; Ziebuhr 2005, 2008). The RTC is anchored through three replicase-gene encoded integral membrane proteins to intracellular membranes derived from the endoplasmic reticulum (Knoops et al. 2008; Masters 2006; Ziebuhr and Snijder 2007). Besides proteins encoded by the replicase gene, the RTC contains the nucleocapsid (N) protein (Almazan et al. 2004; Schelle et al. 2005) and several cellular factors, which have not been characterized in great detail (Shi and Lai 2005; van Hemert et al. 2008). It is becoming increasingly clear that the coronavirus replicase gene also encodes proteins that are not essential for viral RNA synthesis but are involved in viral pathogenicity and specific virus-host interactions (see below).

The single-stranded, positive-sense RNA genome of coronaviruses fulfills a double role, serving as an mRNA for the expression of the replicase gene and a template for the synthesis of genome- and subgenome-length minus-strand RNAs. A large part of the genome (about two-thirds) is occupied by the replicase gene, which consists of two (slightly) overlapping open reading frames (ORF) located in the $5^{\prime}$-proximal region of the viral genome RNA. The remaining $3^{\prime}$-terminal third of the genome is dedicated to encoding the four major structural proteins of the virus (S, E, M, and $\mathrm{N}$ ) and a varying number of so-called accessory proteins (Fig. 6.1). Compared to other coronaviruses, SARS coronavirus (SARS-CoV) encodes an unusually large number of accessory proteins, some of which are involved in counteracting antiviral host responses (Chap. 4). The ORFs located downstream of the SARS-CoV replicase gene are expressed from eight subgenomic (sg) RNAs (Thiel et al. 2003) (Fig. 6.1). A peculiarity of the sgRNAs produced by coronaviruses and some other nidoviruses is that both the plus-strand genome RNA and all plus-strand sgRNAs share a short, so-called leader sequence at their $5^{\prime}$ ends, whose functional relevance is currently unknown (Spaan et al. 1983). It has been speculated that the minus-strand complement of the leader sequence (present at the $3^{\prime}$ ends of all minus-strand RNAs) might facilitate initiation of plus-strand RNA synthesis. Alternatively, the leader might promote the translation of $\operatorname{sgRNAs}$, for example through the presence of sequence elements required for efficient recognition by the viral capping apparatus or other mechanisms enhancing translation initiation. The precise mechanism used to join the "leader" and "body" sequences of sgRNAs (which are located more than $20 \mathrm{~kb}$ apart in the genome) is unknown but is generally accepted to involve a discontinuous step during sg minus-strand RNA synthesis and be guided by complementary base-pairing between transcriptionregulating sequences (for recent reviews, see Pasternak et al. 2006; Sawicki et al. 2007). The specific requirements for maintaining genome RNAs of an unparalleled size and synthesizing sg minus-strand RNAs in a discontinuous manner are reflected by an exceptional complexity of the protein machinery involved in viral RNA synthesis, which will be the topic of this review. With few exceptions, the proteins and mechanisms involved in genome replication and transcription are 


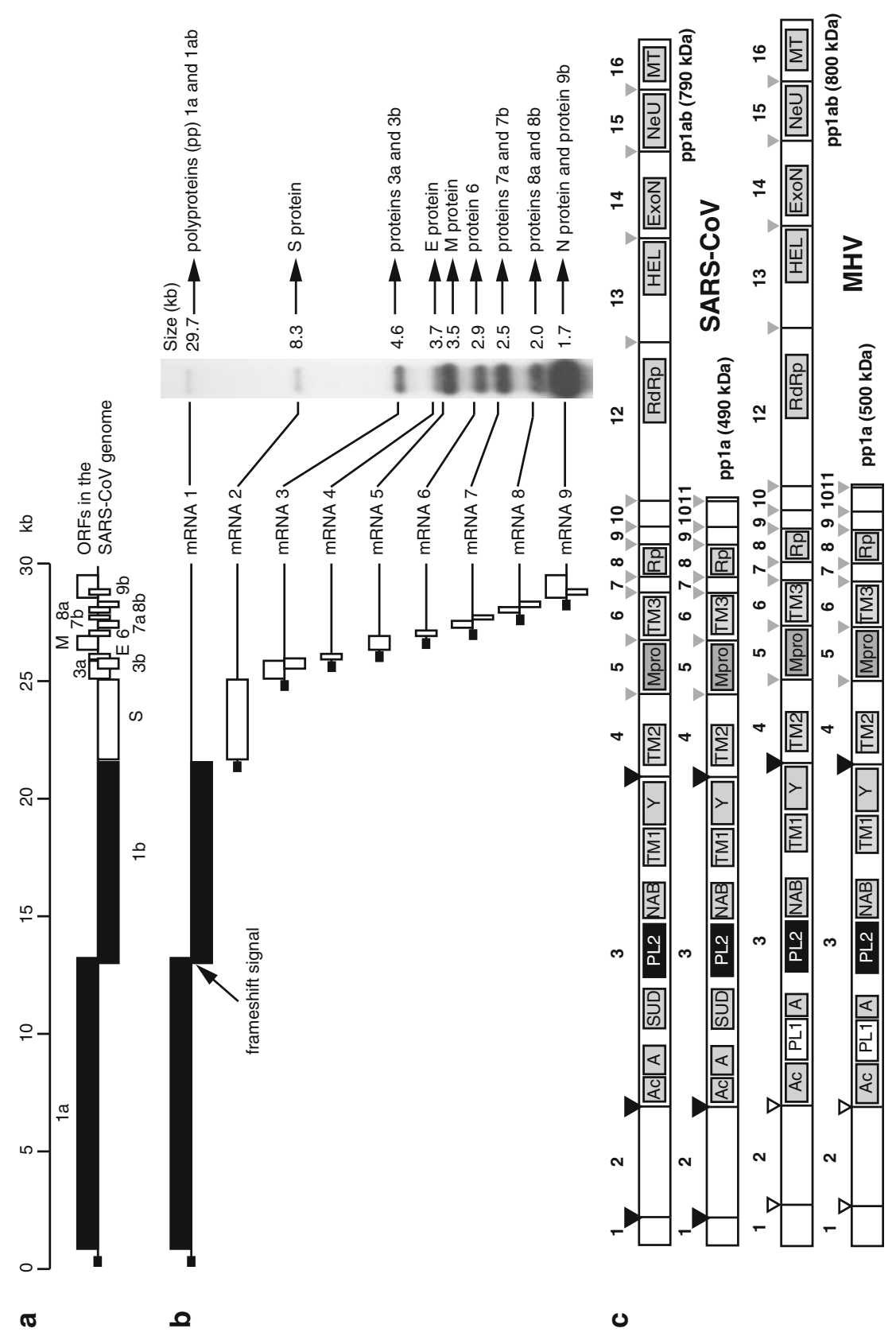


conserved among SARS-CoV and other coronaviruses. In this chapter, we will review recent work on the SARS-CoV RTC and refer to related work on other coronaviruses as appropriate.

\subsection{Organization and Expression of the Coronavirus Replicase Gene}

The SARS-CoV replicase gene contains more than 21,000 nucleotides and is comprised of two ORFs called ORF1a and ORF1b (Fig. 6.1) (Marra et al. 2003; Rota et al. 2003; Thiel et al. 2003). Upon infection of the cell, ORFs 1a and 1b are translated into two large polyproteins, ppla and pplab, of approximately 490 and $790 \mathrm{kDa}$, respectively. Polyprotein $1 \mathrm{ab}$ is a C-terminally extended version of pp1a; pplab expression requires a programmed (-1) ribosomal frameshift prior to termination of ORF1a translation, resulting in continuation of translation in the ORF1b reading frame (Thiel et al. 2003). Frameshifting depends on two cis-acting RNA elements, a "slippery" heptanucleotide sequence and an RNA pseudoknot structure (see Chap. 6 for details). Based on in vitro translation experiments, it has been estimated that frameshifting occurs in roughly $30 \%$ of translation events (Brierley 1995; Dos Ramos et al. 2004; Herold and Siddell 1993; Namy et al. 2006). This results in a considerably higher amount of ORF1a-encoded proteins compared to ORF1b-encoded proteins, which is likely to be of biological relevance as the frameshifting mechanism is conserved in coronaviruses and other nidoviruses.

SARS-CoV ppla and pplab are co- and post-translationally processed by two proteases, a papain-like protease $\left(\mathrm{PL}^{\mathrm{pro}}\right)$ and the main protease $\left(\mathrm{M}^{\mathrm{pro}}, \mathrm{nsp5}\right)$, resulting in 16 mature products called nonstructural proteins (nsps) 1-16

Fig. 6.1 SARS coronavirus (SARS-CoV) genome organization and expression. (a) Open reading frames in the SARS-CoV genome. The replicase gene is comprised of two large open reading frames (ORFs) which are shown in black. (b) RNAs produced in SARS-CoV-infected cells. The $5^{\prime}$-terminal ORF(s) expressed from specific RNAs is/are shown as boxes. The small black box indicates the $5^{\prime}$-leader sequence present on each of the viral RNAs. The replicase gene (ORFs 1a and $1 \mathrm{~b}$ ) are shown in black. To the right, SARS-CoV genomic and subgenomic RNAs as detected by Northern blotting using a $3^{\prime}$ end-specific probe are shown together with information on sizes (in kilobases) and names of proteins expressed from these RNAs. (c) Overview of the domain organization and proteolytic processing of the SARS-CoV replicase polyproteins, pp1a (486 kDa) and pp1ab (790 kDa). For comparison, the mouse hepatitis virus (MHV)-A59 replicase polyproteins are shown. The processing end-products of pp1a are designated nonstructural proteins (nsps) 1 to nsp11 and those of pp1ab are designated nsp1 to nsp10 and nsp12 to nsp16. Cleavage sites that are processed by the viral main protease, $\mathrm{M}^{\mathrm{pro}}$, are indicated by grey arrowheads; sites that are processed by the papain-like proteases 1 and 2 (PL1 and PL2), are indicated by white and black arrowheads, respectively. Ac, acidic domain; A, ADRP (ADP-ribose-1"-phosphatase); SUD, SARS-CoV unique domain; NAB, nucleic acid-binding domain; Rp, noncanonical RNA polymerase (putative primase); RdRp, RNA-dependent RNA polymerase; TM1, TM2, TM3, transmembrane domains 1, 2, and 3, respectively; HEL, helicase; ExoN, $3^{\prime}$-to- $5^{\prime}$ exoribonuclease; $\mathrm{NeU}, \mathrm{NendoU}$ (nidoviral uridylate-specific endoribonuclease); MT, ribose- $2^{\prime}-O$-methyltransferase 
(Harcourt et al. 2004; Prentice et al. 2004; Snijder et al. 2003; Thiel et al. 2003). The $\mathrm{PL}^{\text {pro }}$ domain is part of nsp3 and processes the nsp1|2, nsp2/3 and nsp3|4 cleavage sites. The $\mathrm{M}^{\text {pro }}$ cleaves the $\mathrm{C}$-terminal part of $\mathrm{pp} 1 \mathrm{a} / \mathrm{ab}$ at the remaining 11 sites (Fig. 6.1), releasing the most conserved proteins of the coronavirus RTC. The individual cleavage sites are thought to be processed with varying efficiencies, resulting in the presence of some reasonably stable intermediates. This has been studied in some detail for the proteins released by the PL ${ }^{\text {pro }}$ activity (Harcourt et al. 2004). While the nsp $1 / 2$ and nsp3|4 sites are rapidly processed, the nsp $2 \mid 3$ site was found to be cleaved at a lower rate, giving rise to a relatively long-lived nsp2-3 intermediate in infected cells. The rapid cleavage of the nsp3/4 site results in fast separation of the domains processed by $\mathrm{PL}^{\text {pro }}$ and those processed by $\mathrm{M}^{\text {pro }}$. Even though an initial study of the nonstructural proteins in SARS-CoV-infected cells failed to detect processing intermediates (Prentice et al. 2004), the cleavage of interdomain junctions by $\mathrm{M}^{\text {pro }}$ is also thought to occur at varying rates (Fan et al. 2004). This is supported by data obtained for mouse hepatitis virus (MHV), showing that nsp4-10 is a relatively stable processing intermediate (Schiller et al. 1998). In addition to the sequence of the individual cleavage sites, the efficiency of processing appears to be influenced by the secondary structure of the substrate (Fan et al. 2005, 2004). Thus, cleavage of peptides with a high propensity to form $\beta$-sheets is enhanced, consistent with the substrate binding mode observed in crystal structures of $\mathrm{M}^{\text {pro }}$ in complex with inhibitors (Anand et al. 2003; Yang et al. 2003, 2005).

It is generally accepted that processing intermediates fulfil important functions that, in some cases, differ from those of the fully processed proteins. This strategy is commonly employed by plus-strand RNA viruses to expand the functional repertoire of the relatively small number of protein domains present in viral polyproteins (Dougherty and Semler 1993; Palmenberg 1990). The idea of different functions being associated with precursors and final processing products, respectively, is supported by the fact that coronavirus RNA synthesis requires ongoing protein synthesis, with minus-strand synthesis declining more rapidly than positive-strand synthesis after inhibition of translation by cycloheximide (Sawicki and Sawicki 1986).

\subsection{Functions and Activities of Replicase Gene-Encoded Nonstructural Proteins}

\subsubsection{ORF1a-Encoded Nonstructural Proteins 1-11}

The proteins processed from the N-terminal regions of the coronavirus replicative polyproteins $1 \mathrm{a} / 1 \mathrm{ab}$ are highly divergent among coronaviruses. nsp 1 proteins from group 1 and group 2 coronaviruses, respectively, are not evidently related to each other, whereas group 3 coronaviruses lack an nsp1-counterpart altogether, making 
nsp2 the most $\mathrm{N}$-terminal processing product in this case. The significant sequence diversity is also evident when nsp1 proteins from the same group (1 or 2) are compared with each other (Almeida et al. 2007; Connor and Roper 2007; Snijder et al. 2003). A nuclear magnetic resonance structure was reported for SARS-CoV nsp1 (Almeida et al. 2007). The protein has a complex $\beta$-barrel fold flanked by disordered $\mathrm{N}$ - and $\mathrm{C}$-terminal domains (see Chap.18 for details) and lacks statistically significant structural similarity to other cellular or viral proteins. Although the protein is not required for replication of SARS-CoV and MHV in cell culture (Brockway and Denison 2005; Wathelet et al. 2007; Züst et al. 2007), there is increasing evidence to suggest that the protein has important functions in vivo. SARS-CoV nsp1 was suggested to counteract cellular innate immune responses by inhibiting IFN signaling pathways, and recombinant SARS-CoV with an attenuating mutation in nsp1 was found to decrease the ability of the virus to replicate in cells with an intact IFN response (Wathelet et al. 2007). Narayanan and co-workers (Narayanan et al. 2008) reported that another SARS-CoV nsp1 mutant, but not the wild-type virus, induced high levels of INF- $\beta$, suggesting that nsp1 may also have a role in type I IFN induction, which contradicts findings reported earlier by others (Wathelet et al. 2007; Züst et al. 2007). Characterization of an MHV mutant expressing a C-terminally truncated form of nsp1 showed that the protein is a major pathogenicity factor of this virus (Züst et al. 2007). There is evidence to suggest that MHV nsp1 is involved in counteracting type I IFN signaling and/or the antiviral activities of IFN-induced proteins, whereas a role in suppression of IFN induction seems less likely.

Furthermore, SARS-CoV nsp1 was shown to (1) promote host mRNA degradation, (2) inhibit cellular translation (Kamitani et al. 2006; Narayanan et al. 2008) and (3) affect cell cycling (Wathelet et al. 2007). MHV nsp1 was reported to colocalize (and interact) with other subunits of the viral replicase-transcriptase at the site of viral RNA synthesis but appears to migrate to virion assembly sites at a later stage of infection (Brockway et al. 2004). It remains to be seen if this relocalization is linked to distinct functions of nsp1 at different stages of the replication cycle of MHV and, possibly, other coronaviruses.

For nsp2, no specific function has yet been identified. It has been suggested that nsp2 is a component of SARS-CoV virions (Neuman et al. 2008). The protein is not essential for replication in vitro as deletion of the entire nsp2 coding sequence was tolerated in both SARS-CoV and MHV (Graham et al. 2005). nsp2 deletion mutants grew to slightly reduced titers and RNA synthesis was diminished by about $50 \%$, with all RNA species being equally affected. More recently, it was shown that the replication defects observed in MHV nsp2 deletion mutants could not be compensated by nsp2 expressed from either a subgenomic RNA or from a C-proximal position in the replicase polyprotein, when inserted between nsp13 and nsp14 (Gadlage et al. 2008).

nsp3 is a large, membrane-anchored multidomain protein. Despite significant sequence diversity among coronavirus nsp3 proteins, up to 16 putative functional domains, including ubiquitin-like, metal-binding, nucleic acid-binding, RNA chaperone-like, poly(ADP)-ribose-binding, protease, transmembrane (TM) and other 
conserved domains have been identified in nsp3 (Neuman et al. 2008; Ziebuhr et al. 2001). nsp3 has been proposed to be a major "hub" for protein-protein and proteinRNA interactions between viral and (possibly) cellular macromolecules (Imbert et al. 2008; Neuman et al. 2008). Many of the domains are common to all coronaviruses while some are group- or species-specific (Neuman et al. 2008; Snijder et al. 2003; Ziebuhr et al. 2001).

Among the conserved domains are papain-like proteases $\left(\mathrm{PL}^{\mathrm{pro}} \mathrm{s}\right)$ that cleave the N-terminal part of the polyproteins at up to three sites (Fig. 6.1). While most coronaviruses possess two PL ${ }^{\text {pro }}$ s (PL1 ${ }^{\text {pro }}$ and PL2 ${ }^{\text {pro }}$ ), SARS-CoV and IBV encode only one active $\mathrm{PL}^{\text {pro }}$, which are orthologues of the PL2 ${ }^{\text {pro }}$ of other coronaviruses (Snijder et al. 2003; Thiel et al. 2003; Ziebuhr et al. 2001). The SARS-CoV PL ${ }^{\text {pro }}$ employs a Cys-His-Asp catalytic triad and exhibits a narrow substrate specificity, with all three processing sites conforming to the consensus sequence LXGG (Harcourt et al. 2004; Thiel et al. 2003). Besides its important role in pp1a/pp1ab processing, the SARS-CoV PL ${ }^{\text {pro }}$ has deubiquitinating activity (Barretto et al. 2005; Lindner et al. 2005) and shares structural features with cellular ubiquitin-specific proteases (see Chap. 18 for details) (Ratia et al. 2006; Sulea et al. 2005). The PL2 ${ }^{\text {pro }}$ homolog of HCoV-NL63, a group $1 \mathrm{~b}$ coronavirus, also has ubiquitin-specific protease activity (Chen et al. 2007b), suggesting that this activity may be of general biological relevance to the coronavirus life cycle. SARS-CoV PL ${ }^{\text {pro }}$ removes ubiquitin and ubiquitin-like modifiers (Ubl) from fusion proteins and debranches polyubiquitin chains, with a marked preference for Lys-48- over Lys-63-conjugated chains (Lindner et al. 2007). The C-terminal residues of ubiquitin and the ubiquitinlike modifier ISG15, LRLRGG, match the consensus sequence of SARS-CoV PL pro cleavage sites in pp1a/pplab very well (Harcourt et al. 2004; Thiel et al. 2003). SARS-CoV PL ${ }^{\text {pro }}$ is able to distinguish between ISG15 and ubiquitin and preferentially cleaves ISG15-modified proteins. The exact mode of recognition of Ubl modifiers by $\mathrm{PL}^{\text {pro }}$ is not known but might involve interactions between the $\mathrm{Zn}^{2+}$ ribbon domain connecting the $\alpha$ and $\beta$ subdomains of the $\mathrm{PL}^{\text {pro }}$ and the $\beta$-grasp fold of ubiquitin and additional, currently unknown, interactions. The deubiquitinating and deISGylating activities of PL ${ }^{\text {pro }}$ have been speculated to be involved in (1) protecting viral and/or cellular proteins from degradation and (2) counteracting innate immune responses (Lindner et al. 2007; Sulea et al. 2005). Recently, PL ${ }^{\text {pro }}$ was shown to inhibit IFN signaling by binding to IRF-3 and interfering with its hyperphosphorylation, dimerization and nuclear translocation (Devaraj et al. 2007). Surprisingly, the inhibition of IFN response was not abrogated by substitution of $\mathrm{PL}^{\text {pro }}$ active-site residues, suggesting that the protease/deubiquitylase activity of $\mathrm{PL}^{\text {pro }}$ was not involved. Slightly contrasting data were reported by Zheng and coworkers (Zheng et al. 2008). In this case, the reduction of the type I INF response induced by vesicular stomatitis virus was dependent on the proteolytic activity of the SARS-CoV PL ${ }^{\text {pro }}$.

Another nsp3 domain is the ADP-ribose $1^{\prime \prime}$ phosphatase (ADRP) domain (also called $\mathrm{X}$ domain or macro domain) (Fig. 6.1). The domain is conserved across members of the genera Coronavirus, Torovirus and Bafinivirus (Draker et al. 2006; Schütze et al. 2006) and several other plus-strand RNA viruses 
(Gorbalenya et al. 1991). Viral ADRPs are related to a large family of macro domain proteins found in many cellular organisms. The protein family is named after the nonhistone domain of macroH2A histones. Macro domain proteins share a conserved fold and bind to (and, in some cases, process) a range of substrates related to ADP-ribose (Karras et al. 2005). Several members of the macro domain family have been shown to (1) bind poly(ADP)-ribose and/or poly(A) RNA and (2) hydrolyze ADP-ribose-1" -phosphate (Egloff et al. 2006; Karras et al. 2005; Neuvonen and Ahola 2009; Putics et al. 2005, 2006; Saikatendu et al. 2005; Xu et al. 2009). The ADRP domains of HCoV-229E, SARS-CoV and transmissible gastroenteritis virus (TGEV) have been shown to hydrolyze ADP-ribose-1"phosphate to yield ADP-ribose and inorganic phosphate (Egloff et al. 2006; Karras et al. 2005; Neuvonen and Ahola 2009; Putics et al. 2005, 2006; Saikatendu et al. 2005; Xu et al. 2009). The molecular mechanisms of the dephosphorylation reaction have not been elucidated but are thought to differ from other phosphatases as there is no sequence and/or structural similarity between the respective enzymes (Allen et al. 2003; Egloff et al. 2006). Based on the structure of coronavirus ADRPs in complex with ADP-ribose, two conserved residues (Asn and His) were proposed to be important for activity (Egloff et al. 2006; Saikatendu et al. 2005; Xu et al. 2009). Substitutions of these residues by alanine abolished ADRP activity activity in an in vitro assay, supporting their critical role (Egloff et al. 2006; Putics et al. 2005).

The biological role of the ADRP in the coronavirus life cycle has not been established. Characterization of an HCoV-229E mutant (HCoV-229E-N1305A) expressing an inactive ADRP revealed no apparent defects in virus reproduction and RNA synthesis in a cell culture system (Putics et al. 2005). Similar observations were made for the corresponding MHV-A59 mutant (MHV-N1348A) (Eriksson et al. 2008), confirming that ADRP activity is dispensable for coronavirus replication in vitro. However, when characterized in vivo, the MHV-N1348A mutant was found to be attenuated. At high infection doses, the mutant and wild-type viruses replicated to similar titers in the liver of C57BL/6 mice but, in contrast to wild-type virus, the N1348A mutant failed to cause severe liver pathology. Similar observations were made in C57BL/6 IFNAR ${ }^{-/}$mice, arguing against a major role of the ADRP activity in counteracting IFN- $\alpha$ host responses. The underlying mechanisms for the observed low pathogenicity of the MHV-N1348A mutant in the liver have not been identified conclusively but may be linked to a reduced expression of proinflammatory cytokines, in particular IL-6. The data support the biological relevance of the catalytic activity of coronavirus ADRP domains which, on the basis of in vitro observations, has previously been questioned by others (Egloff et al. 2006; Neuvonen and Ahola 2009). The biologically relevant substrate(s) of the ADRP domains of SARS-CoV and other coronaviruses remain(s) to be identified. There is increasing evidence to suggest that macro domains have evolved different functionalities using a conserved fold and may have more than one activity which might not necessarily be mutually exclusive in any one domain. A striking example to support this idea is the recent identification of another macro domain within the SARS-CoV nsp3, located downstream of the ADRP (Chatterjee 
et al. 2009) and representing the central domain (SUD-M) of the SARS-CoV unique domain (SUD). On the basis of the NMR structure of SUD-M the ADRP was identified as the closest structural homolog of SUD-M, even though the sequence similarity between the two domains is very low (5\% identical residues). It is tempting to speculate that the SUD-M domain may have evolved from ADRP through gene duplication, similar to what was previously proposed for the two paralogous PL ${ }^{\text {pro }}$ domains found in many coronaviruses (Ziebuhr et al. 2001). SUDM was found to bind to single-stranded poly(A)-RNA while others (Tan et al. 2007) had previously reported a poly $(\mathrm{dG}) / \mathrm{poly}(\mathrm{G})$-binding activity for SUD. The reasons for these differences are currently unclear but might be due to the different domain boundaries of the proteins characterized in the two studies. The full-length SUD has also been shown to have metal-binding activity (Neuman et al. 2008) which likely resides in the $\mathrm{N}$-terminal part of the protein and involves some of the six conserved cysteine residues (SARS-CoV nsp3 positions 393, 456, 492, 507, 550, and 623) and two conserved histidine residues (positions 539 and 613).

Additional domains with nucleic acid-binding activity are present in SARS-CoV nsp3 and probably other coronaviruses. The bacterially-expressed N-terminal domain of nsp3 consistently copurified with nucleic acids (Serrano et al. 2007). The N-terminal region of nsp3 is particularly rich in acidic residues and is therefore also referred to as acidic (Ac) domain (Ziebuhr et al. 2001). The domain is conserved in all coronaviruses but exhibits a low degree of sequence identity (Serrano et al. 2007). The NMR structure of the Ac domain revealed an N-terminal ubiquitin-like fold (residues 1-112) followed by a disordered tail particularly rich in glutamic acid residues (Serrano et al. 2007). The N-terminal globular domain differs from the ubiquitin-like fold by an elongated $\alpha 2$ helix and the presence of two additional helices, $\alpha 3$ and $3_{10}$, which are important for RNA binding. The protein was found to preferentially bind $(\mathrm{G}) \mathrm{AU}(\mathrm{A})$ sequences.

A further domain linked to RNA binding was identified in SARS-CoV nsp3 just downstream of the PL ${ }^{\text {pro }}$ (Neuman et al. 2008). This domain, named nucleic acidbinding domain (NAB), is conserved in group 2 and 3 (but not in group 1) coronaviruses. Bacterially-expressed NAB exhibited ATP-independent doublestranded nucleic acid-unwinding activity, consistent with a possible chaperone function.

Coronavirus replication takes place at virus-induced double membrane vesicles (DMVs) (Gosert et al. 2002; Knoops et al. 2008). The TM domain present in nsp3 (Neuman et al. 2008; Snijder et al. 2003; Ziebuhr et al. 2001), along with TM domains in nsp4 and nsp6, is thought to be involved in tethering the viral replication-transcription complex to intracellular membranes. The topology of the SARSCoV nsp3 TM domain was recently determined (Oostra et al. 2008). The data suggest that the $\mathrm{N}$ - and $\mathrm{C}$-termini are located in the cytoplasm, thus placing the $\mathrm{PL}^{\text {pro }}$ at the same face of the membrane as all its cleavage sites in pp1a/pp1ab. The domain traverses the membrane twice, while the third, central, predicted transmembrane helix does not appear to function as such. By analogy with the TM domains located in the equine arteritis virus nsp2 and nsp3 proteins (Snijder et al. 2001), whose role in DMV formation has been established earlier, Oostra and co-workers 
(Oostra et al. 2007, 2008) suggest that DMV formation in SARS-CoV infected cells is mediated by nsp3 and nsp4. They further hypothesize that the central non-TM hydrophobic domain might play an important role in this process by dipping into the membrane and inducing curvature of the membranes.

nsp4 is a tetra-spanning membrane protein (Oostra et al. 2008). Both termini are located in the cytoplasm (Oostra et al. 2007). TM helices 1 and 2 are connected by a long lumenal loop that is N-glycosylated (Oostra et al. 2007). The presumed critical role of nsp4 in DMV formation is supported by studies using a temperaturesensitive mutant of MHV-A59 in which substitution of the nsp4 Asn-258 residue with Thr led to impaired DMV formation, while polyprotein processing was not affected (Clementz et al. 2008). The critical role of nsp4, including its transmembrane-spanning regions $1-3$, in coronavirus replication has been established in a recent reverse genetics study using MHV-A59 (Sparks et al. 2007). The study also showed that the C-terminal nsp4 residues Lys-398 to Thr-492 are dispensable for MHV replication.

nsp5 is the viral main protease $\left(\mathrm{M}^{\mathrm{pro}}\right)$. It cleaves at 11 sites in the central and $\mathrm{C}$ terminal pp1a/pp1ab regions (Thiel et al. 2003; Ziebuhr et al. 1995; Ziebuhr et al. 2000). Because of its prominent role in pp1a/pp1ab processing and the large body of structural and biochemical information available for this enzyme, the $\mathrm{M}^{\text {pro }}$ is considered an attractive target for the development of antivirals. The enzyme is distantly related to the $3 \mathrm{C}$ proteases of picornaviruses (hence its traditional name "3C-like protease," $3 \mathrm{CL}^{\text {pro }}$ ) but diverged significantly from these viral homologs (Gorbalenya et al. 1989b). For example, in place of the typical Cys-His-Asp/Glu catalytic triad of picornaviral $3 \mathrm{C}$ proteases, the coronavirus $\mathrm{M}^{\text {pro }}$ employs a CysHis catalytic dyad (Anand et al. 2003, 2002; Tan et al. 2005; Xue et al. 2008; Yang et al. 2003, 2005; Zhao et al. 2008). A water molecule was found to occupy the position of the third member of the catalytic triad in coronavirus $\mathbf{M}^{\text {pro }}$ structures and it has been suggested that this water molecule might stabilize the protonated His during catalysis. In common with many cellular and viral chymotrypsin-like proteases, coronavirus $\mathrm{M}^{\text {pro }}$ has a two- $\beta$-barrel fold which, in the coronavirus enzymes, is linked to a unique $\alpha$-helical domain at the C-terminus (Anand et al. 2002). $\mathrm{M}^{\text {pro }}$ forms homodimers (Anand et al. 2003, 2002; Yang et al. 2003). Dimerization mainly occurs through interactions between the C-terminal domains of the two protomers in the dimer as well as a stretch of $\mathrm{N}$-terminal residues ( $\mathrm{N}$-finger) (see Chap. 9 for details). Dimerization is generally believed to be a prerequisite for trans-processing activity. The dimeric structure is another feature that sets the coronavirus $\mathrm{M}^{\text {pro }}$ apart from $3 \mathrm{C}$ proteases which function as monomers. Over the past few years a large number of studies have provided significant insight into the structural details and dynamics of $\mathbf{M}^{\text {pro }}$ dimerization and their functional consequences. For a review of this work, the reader is referred to Chap. 9.

nsp6 is another TM protein. Both the $\mathrm{N}$ - and C-terminus are located cytoplasmically (Oostra et al. 2008), indicating an even number of TM helices and thus placing the $\mathrm{M}^{\text {pro }}$ on the same face of the membrane as all its substrates. The protein has seven putative TM helices. To satisfy the observed $\mathrm{N}_{\text {endo }}-\mathrm{C}_{\text {endo }}$ localization of the protein, Oostra and co-workers (2008) proposed that only six of the predicted TM 
helices function as such in the context of the full-length protein and helix 6 or possibly helix 7 might not traverse the membrane. Further, it has been suggested that the nonmembrane-spanning helix may act as interaction platform for other replicase components or aid in the formation of DMVs. The function of nsp6 remains to be characterized.

nsp8 was recently reported to be a second "noncanonical" RNA-dependent RNA polymerase (Imbert et al. 2006) (see Chap. 18). The protein synthesizes short oligonucleotides of up to $6 \mathrm{nts}$ and requires an RNA template and metal ions for activity. RNA synthesis was sequence specific, with a preference for the internal $5^{\prime}$ $(\mathrm{G} / \mathrm{U}) \mathrm{CC}-3^{\prime}$ trinucleotide sequence as site of initiation, but exhibited a relatively low fidelity and processivity. nsp 8 is well conserved among coronaviruses. The noncanonical $\mathrm{RdRp}$ is therefore suggested to be an essential enzymatic activity involved in RNA synthesis in all coronaviruses and, possibly, other related nidoviruses. Imbert and co-workers (Imbert et al. 2006) hypothesized that nsp8 could act as a primase that produces RNA primers which are then extended by the main $\mathrm{RdRp}, \mathrm{nsp} 12$, in a mechanism reminiscent of DNA replication.

nsp8 was shown to interact with nsp7 and together these proteins form a hexadecameric ring structure consisting of eight copies of each protein as shown by X-ray crystallography (Zhai et al. 2005). The complex encircles a channel with a diameter of $\sim 30 \AA$ that is lined with positively-charged residues (for details, see Chap. 18). Addition of nsp7 to the primase activity assay did not increase the primase activity. However, nsp8 exhibits a low thermostability and nsp7 might therefore act as a stabilizing mortar (Imbert et al. 2006; Zhai et al. 2005).

The structure of SARS-CoV nsp9 was solved by two groups (Egloff et al. 2004; Sutton et al. 2004). A distant structural relationship with domain II of the $\mathrm{M}^{\text {pro }}$ was noted, suggesting that both proteins may be evolutionary related and thus represent another example of domain duplication in the coronavirus replicase, similar to what was discussed above for coronavirus PL ${ }^{\text {pro }}$ and macro domains. Furthermore, nsp9 is structurally related to proteins containing an oligosaccharide/oligonucleotidebinding (OB) fold, although the connectivity of the individual secondary structural elements differs in nsp9. A large proportion of OB-fold proteins bind nucleic acids and SARS-CoV nsp9 was confirmed to also bind ssRNA. Binding of ssRNA by nsp9 was unspecific but specificity might possibly be attained by interaction with other viral or cellular proteins. Sutton and co-workers (2004) showed that SARSCoV nsp9 interacts with nsp8 in an analytical ultracentrifugation analysis. The experiment further suggested that this interaction might help stabilize an otherwise disordered domain of nsp8. nsp9 forms dimers through the interaction of parallel $\alpha$-helices that contain a GXXXG protein-protein interaction motif (Miknis et al. 2009). Substitutions of either of the Gly residues with Glu disrupted dimer formation while RNA binding was only marginally affected. Viable SARS-CoV mutants carrying either mutation could not be recovered, suggesting that nsp9 dimerization is critical for virus replication.

nsp10 is another small replicase protein with RNA-binding activity. Two studies analyzing the structure of nsp10 described a single-domain protein that contains two $\mathrm{Zn}^{2+}$-fingers (Joseph et al. 2006; Su et al. 2006). nsp10 was shown to bind 
single- and double-stranded RNA and DNA with low affinity and no apparent specificity. nsp10 interacts with nsp9 as shown by cross-linking (Joseph et al. 2006) and in a GST-pulldown assay (Imbert et al. 2008). As nsp9, in turn, interacts with nsp8 and nsp8 forms a complex with nsp 7 and all these proteins are involved in homotypic interactions (see above and Chap. 18), it is tempting to believe that these proteins form a multiprotein complex that, in the course of infection, undergoes structural rearrangements (possibly due to $\mathrm{M}^{\text {pro }}$-mediated cleavages), thereby activating, modulating or inactivating specific RTC function(s) as required at the various steps of viral RNA synthesis.

Consistent with the presumed key role of $\mathrm{M}^{\text {pro }}$ processing in the formation of a functional RTC, viable MHV mutants could not be recovered if cleavage at the nsp7|8, nsp8|9 or nsp10|11(12) sites was abolished (Deming et al. 2007). Disruption of proteolytic processing at the nsp9|10 site gave rise to an attenuated, but viable phenotype. The MHV nsp9110 cleavage site mutant restored near wild-type growth kinetics after serial passaging which was not caused by restoration of processing at the nsp9l10 site but by a number of compensatory mutations at distant positions in the viral genome. This suggests that nsp9-10 can function as a fusion protein, though efficient replication requires adaptation of the virus. The functional role of the specific changes identified in some of the recovered viruses remain to be characterized.

nsp1 1 forms the C-terminal part of pp1a. SARS-CoV nsp11 is an oligopeptide of 13 residues. It is produced if no programmed frameshift occurs at the "slippery sequence" (see Chap. 6), leading to translation termination at the ORF1a stop codon. nsp11 shares its N-terminal amino acids (upstream of the frameshift site) with nsp12. Most of the nsp11 coding sequence overlaps with the RNA sequence involved in frameshifting and the nsp12 coding sequence, posing severe constraints on the nsp11 sequence and arguing against a functional role of nsp11. The protein has also not been detected in infected cells.

\subsubsection{ORF1b-Encoded Nonstructural Proteins 12-16}

The RNA-dependent RNA polymerase (RdRp, nsp12) is the most conserved protein of the coronavirus replicase-transcriptase. Expression of nsp12 (and all other ORF1b-encoded proteins) requires ribosomal frameshifting, implying that nsp12-16 are produced at significantly lower levels compared to ORF1a-encoded functions. SARS-CoV nsp12 is a protein of 932 residues. The actual catalytic domain containing the conserved RdRp motifs (Gorbalenya et al. 1989b; Koonin 1991) occupies the C-terminal region (C-terminal domain, CTD) of nsp12 while the N-terminal domain (NTD) spanning the first 375 amino acids has no known counterpart in other RdRps (Xu et al. 2003). Xu and co-workers (2003) proposed a three-dimensional (3D) homology model for the SARS-CoV nsp12 CTD. This model showed the characteristic cupped right hand palm-finger-thumb structure encircling a nucleic acid-binding tunnel. The RdRp activity of nsp12 was recently 
confirmed by showing that bacterially-expressed nsp12 is able to extend an oligo (U) primer hybridized to a poly(A)-template (Cheng et al. 2005).

SARS-CoV nsp13 is a multidomain protein of 601 amino acid residues. The $\mathrm{N}$-terminal region contains a zinc-binding domain (ZBD) while a helicase domain featuring the typical conserved morifs of superfamily 1 helicases is present in the C-terminal half (Gorbalenya et al. 1989a, 1989b). The ZBD contains 12 conserved cysteine and histidine residues that are predicted to form a binuclear $\mathrm{Zn}^{2+}$-binding cluster (Seybert et al. 2005; van Dinten et al. 2000). It is conserved in all nidoviruses and is critical for helicase activity in vitro (Seybert et al. 2005) and RNA synthesis of HCoV-229E in cell culture (Hertzig and Ziebuhr, unpublished). Coronavirus helicases (including SARS-CoV nsp13) were shown to unwind RNA and DNA duplexes in a $5^{\prime}$-to- $3^{\prime}$ direction with respect to the single-stranded RNA they initially bind to (Ivanov and Ziebuhr 2004; Ivanov et al. 2004a; Seybert et al. 2000; Tanner et al. 2003). Translocation of nsp13 along RNA (and concomitant duplex unwinding) is fueled by NTP or dNTP hydrolysis. Consistent with many other helicases, the nsp13-associated NTPase/dNTPase activity is stimulated by nucleic acids (Heusipp et al. 1997). Additionally, nsp13 exhibits RNA 5'-triphosphatase activity which was proposed to catalyze the first step of the $5^{\prime}$-capping reaction of viral RNAs (Ivanov and Ziebuhr 2004; Ivanov et al. 2004a).

The N-terminal part of nsp14 contains a $3^{\prime}$-to- $5^{\prime}$ exoribonuclease (ExoN) domain. ExoN is related to the DEDD superfamily of exonucleases (Zuo and Deutscher 2001) but carries an additional putative $\mathrm{Zn}^{2+}$-finger structure that is inserted between the conserved motifs II and III (Snijder et al. 2003). The ExoN activity of SARS-CoV nsp14 was demonstrated in vitro and shown to be specific for single-stranded and double-stranded RNA (Minskaia et al. 2006). The protein was shown to require metal ions for activity and isothermic titration calorimetry data suggest that nsp14 binds two $\mathrm{Mg}^{2+}$ ions per molecule (Chen et al. 2007a). This data, together with the profound reduction of activity upon substitution of putative metal ion-coordinating residues (Minskaia et al. 2006), suggests that catalysis occurs through a two-metal-ion mechanism similar to that used by many cellular enzymes mediating phosphoryltransfer reactions (Beese and Steitz 1991).

It has been proposed that coronaviruses and other nidoviruses with genome sizes of about $30 \mathrm{~kb}$ have evolved specific mechanisms to replicate their large RNA genomes. The argument is that, in the absence of such mechanisms, the intrinsically error-prone RdRps of RNA viruses would cross a (postulated) threshold of nucleotide misincorporations above which the survival of a given virus population becomes impossible. The question of how coronaviruses are able to maintain their exceptionally large RNA genomes has not been resolved but a number of recent observations suggest that nsp14 was critically involved in the evolution of these large genomes. First, coronaviruses were shown to encode a $3^{\prime}$-to-5' ExoN that is related to cellular enzymes involved in proof-reading mechanisms during cellular DNA replication. Second, the ExoN activity is not conserved in nidoviruses with much smaller genomes (i.e., Arteriviridae), even though the ppla/pplab domain organization is otherwise very well conserved among small and large nidoviruses (Gorbalenya et al. 2006; Snijder et al. 2003). 
Third, ExoN activity was found to be essential for HCoV-229E replication in cell culture (Minskaia et al. 2006). Transfection of genome-length RNAs containing substitutions of ExoN active-site residues failed to produce viable virus. Northern blot analysis of viral RNA in transfected cells revealed a severe reduction in genome replication, an altered molar ratio of sgRNAs and aberrant migration of two sgRNAs in some of the mutants (Minskaia et al. 2006). Consistent with these data, deletion of the ExoN domain from a SARS-CoV replicon was reported to abolish RNA synthesis and substitution of a putative ExoN active-site residue reduced genome replication and transcription about 10-fold in this system (Almazan et al. 2006). Fourth, the characterization of MHV-A59 ExoN active-site mutants revealed defects in viral RNA synthesis and rapid accumulation of mutations across the genome (Eckerle et al. 2007). The authors calculated that, during passage (and under strong selection pressure), MHV-A59 ExoN mutants accumulated approximately 15 -fold more substitutions than the wild-type virus. The data obtained in these studies are consistent with the proposed role of ExoN in increasing the fidelity of the coronavirus $\mathrm{RdRp}$, although there is still no direct proof for this specific function.

Coronaviruses encode a second conserved ribonuclease, NendoU (Nidoviral endoribonuclease, specific for $\mathrm{U}$ ), which is located within nsp15 (Snijder et al. 2003). The domain is conserved not only in coronaviruses but also in all other members of the order Nidovirales. NendoU homologs could not be identified in any other RNA virus, which makes the domain a genetic marker of nidoviruses (Ivanov et al. 2004b). SARS-CoV nsp15 was shown to be an endoribonuclease that cleaves preferentially $3^{\prime}$ of uridylates and generates $2^{\prime}-3^{\prime}$ cyclic phosphate ends (Bhardwaj et al. 2004; Ivanov et al. 2004b). The activity is significantly enhanced by $\mathrm{Mn}^{2+}$ while addition of $\mathrm{Mg}^{2+}$ or $\mathrm{Ca}^{2+}$ only had minor effects on activity. The structure of SARS-CoV nsp15 revealed a novel fold (see Chap. 18). In spite of unrelated structures and lack of sequence similarity, nsp15 and RNaseA were proposed to use the same catalytic mechanism (Ricagno et al. 2006). Residues forming the catalytic triad of bovine RNase A (His-12, Lys-41, His-119) could be superimposed with His/Lys residues known to be critical for activity of SARS-CoV nsp15 (Ivanov et al. 2004b) and both RNaseA and SARS-CoV NendoU generate $2^{\prime}-3^{\prime}$ cyclic phosphate ends, suggesting that endoribonucleolytic cleavage by NendoU proceeds through the same catalytic mechanism (Ricagno et al. 2006). The proposed RNaseA-like catalytic mechanism does not involve metal ions and therefore the observed stimulatory effects of $\mathrm{Mn}^{2+}$ on NendoU activities of several (but not all) coronaviruses (Bhardwaj et al. 2004; Cao et al. 2008; Ivanov et al. 2004b; Xu et al. 2006) cannot readily be reconciled with a role in catalysis. Based on intrinsic tryptophan fluorescence data, Bhardwaj and co-workers (2004) suggested that $\mathrm{Mn}^{2+}$ ions induce specific conformational changes in the protein that might promote its nuclease activity. However, the available crystal structure information does not provide evidence for the presence of $\mathrm{Mn}^{2+}$ ion-binding sites in any of the coronavirus NendoUs studied (Ricagno et al. 2006; Xu et al. 2006). More recently, it was suggested that $\mathrm{Mn}^{2+}$ ions increase the RNA-binding activity of NendoU (Bhardwaj et al. 2006). 
Coronavirus NendoUs form hexamers consisting of a dimer of trimers in crystals and in solution (see Chap. 18). Amino acid substitutions that interfere with hexamerization were reported to reduce the nucleolytic activity and RNA affinity of SARS-CoV NendoU, suggesting that hexamerization is critically involved in activity (Guarino et al. 2005). However, the presence of six independent active sites in the NendoU crystal structure, together with relatively minor differences in the $K_{\mathrm{m}}$ and $k_{\text {cat }}$ values determined for monomeric and hexameric MHV NendoU (Xu et al. 2006) and the fact that maltose-binding protein-NendoU fusion proteins that are unable to form hexamers possess endoribonucleolytic activity (Ivanov et al. 2004b) suggest that hexamerization may not be essential for activity. It therefore remains possible that NendoU may be active prior to its proteolytic release from pplab, for example in the context of NendoU-containing processing intermediates or the fulllength polyprotein.

The role of NendoU in the coronavirus life cycle is not well understood. Reverse genetics data obtained for HCoV-229E (Ivanov et al. 2004b) and MHV (Kang et al. 2007) suggest that NendoU activity is not essential for viral replication. Substitutions of NendoU active-site His and Lys residues in MHV were shown to cause subtle defects in sgRNA accumulation and reduce virus titers by about 10-fold. Substitutions of a conserved Asp residue abolished viral RNA synthesis, both in HCoV-229E and MHV (Ivanov et al. 2004b; Kang et al. 2007). Both structural information and biochemical data suggest that this particular residue may have an important structural role, suggesting that the observed defects in viral replication may be due to misfolding of nsp15 or other pp1a/pp1ab subunits rather than caused by the lack of NendoU activity. More studies are needed to understand the function of the conserved NendoU activity in nidoviral replication.

NendoU belongs to a family of proteins that is prototyped by a cellular endoribonuclease, called XendoU, from Xenopus laevis (Laneve et al. 2003). XendoU is a poly(U)-specific endoribonuclease that, together with ExoN and methyltransferase (MT) activities, is involved in the processing of intron-encoded small nucleolar (sno) RNAs and site-specific RNA methylation pathways in X. laevis oocytes (Laneve et al. 2003). It has been suggested (but not yet explored experimentally) that a similar set of activities associated with coronavirus nsp14 (ExoN), nsp15 (NendoU) and nsp16 (MT), which are coexpressed in the C-proximal pplab region, may be involved in related RNA-processing and methylation pathways (Snijder et al. 2003).

The most C-terminal processing product of pp1ab, nsp16, has been proposed to be related to the RrmJ/FtsJ family of $S$-adenosyl-methionine-dependent ribose2'-O-methyltransferases (Feder et al. 2003; Snijder et al. 2003). The predicted MT activity was recently confirmed for nsp16 of feline coronavirus (FCoV) (Decroly et al. 2008). FCoV nsp16 was shown to methylate ${ }^{7 \mathrm{Me}} \mathrm{GpppAC}_{\mathrm{n}}$ at the ribose-2'-O moiety of the adenosine, converting a cap-0 to a cap- 1 structure. The domain is critically involved in coronavirus replication as deletion or ablation of expression of nsp16 abolished RNA synthesis in SARS-CoV (Almazan et al. 2006) and HCoV-229E (Hertzig, Schelle and Ziebuhr, unpublished data) while substitution of one of the residues forming the catalytic tetrad reduced sgRNA synthesis about 
10-fold in a SARS-CoV replicon system (Almazan et al. 2006). The 5'-cap structure is known to be critically important for the stability of cellular mRNAs and translation initiation (reviewed in Shuman 2001). The cellular capping apparatus is located in the nucleus, implying that viruses that replicate in the cytoplasm need to either provide all the enzymes required to produce RNA cap structures or employ alternative mechanisms, such as cap snatching (Plotch et al. 1981). In eukaryotic cells, the production of ${ }^{7 \mathrm{Me}} \mathrm{GpppG}_{2^{\prime} O M \mathrm{Me}} \mathrm{N}_{\left(2^{\prime} O \mathrm{Me}\right)}$ cap-1 (and cap-2) structures is achieved through four consecutive enzymatic reactions: (1) removal of the RNA $5^{\prime} \gamma$-phosphate by an RNA $5^{\prime}$-triphosphatase, (2) transfer of GMP to the remaining $5^{\prime}$ diphosphate end by a guanylyltransferase, (3) methylation of the guanine at the N7 position by a guanine-N7-methyltransferase, resulting in a cap0 structure, (4) methylation of ribose- $2^{\prime}-O$-moieties of the first (and second) nucleotide of the mRNA by a ribose- $2^{\prime}-O$-methyltransferase, resulting in cap- 1 and cap-2 structures, respectively (Langberg and Moss 1981; Shuman 2001). Coronaviral RNAs are modified at the $5^{\prime}$-end, probably with a cap structure (Lai et al. 1982), and it seems reasonable to suggest that the nsp16-associated ribose- $2^{\prime}$ $O$-methyltransferase activity catalyzes the conversion of cap- 0 into cap- 1 structures whereas the nsp13-associated RNA 5'-triphosphatase activity might catalyze the first step of $5^{\prime}$-cap formation (Ivanov and Ziebuhr 2004; Ivanov et al. 2004a). Homologs of cellular guanylyltransferase and guanine-N7-methyltransferases have not been identified in coronaviruses and it remains to be seen what viral or cellular proteins/activities mediate the two remaining reactions, namely GMP transfer and guanine-N7 methylation, to synthesize RNA cap structures on coronavirus RNAs. While some + RNA viruses, such as alphaviruses, encode all four required activities (reviewed in Salonen et al. 2005), other viruses use one and the same domain to perform two different reactions. For example, the West Nile virus MT methylates at both the guanine $\mathrm{N} 7$ position and the ribose- $2^{\prime}-O$ moiety using an interesting substrate-repositioning mechanism and a single $S$-adenosylmethionine-binding site (Dong et al. 2008). While FCoV nsp16 had no guanineN7-methyltransferase activity and did not bind unmethylated $\operatorname{GpppAC}_{n}$ (Decroly et al. 2008) the authors point out that recognition of unmethylated, guanylylated RNA might depend on regulatory RNA elements located further downstream in the RNA, similar to what was described for flaviviruses (Dong et al. 2007; Ray et al. 2006).

\subsection{Future Directions}

The emergence of SARS-CoV led to a renewed interest in coronavirology and recent years saw a significant increase in research involving this family of viruses. Many of the previously predicted coronavirus replicase gene-encoded enzyme activities were characterized by biochemical and structural approaches using viral proteins expressed in heterologous systems (Ziebuhr 2008). In a few cases, 
structural studies informed subsequent biochemical studies, resulting in the identification of RNA-binding domains and other functions (Egloff et al. 2004; Joseph et al. 2006; Zhai et al. 2005).

Most of the biochemical and structural studies reported over the past years involved isolated nsps or subdomains of these proteins rather than multidomain complexes. Although these studies provided invaluable new insight into structurefunction relationships of many of these proteins, there is hardly any information regarding the quarternary structure(s) and subunit compositions of replicase and/or transcriptase complexes catalyzing specific reactions during viral RNA synthesis. For example, very little is known about the special factors and macromolecular interactions involved in discontinuous minus-strand RNA synthesis, a unique feature of coronaviruses and several other nidoviruses. Similarly, the replication and maintenance of the exceptionally large coronavirus genome is likely to involve the concerted action of replicase gene-encoded nsps, possibly including processing precursors and intermediates as pointed out above. The physical and functional interactions between the various components of the replicase-transcriptase probably undergo significant changes in the course of the viral replication cycle, further complicating the characterization of these complexes. Despite these major technical challenges, recent studies increasingly try to elucidate the functions and structures of complexes involving two or more proteins (Zhai et al. 2005). Also, the availability of reverse genetics systems for several coronaviruses has greatly facilitated the characterization of specific protein functions and critical interactions between domains encoded by very different regions of the replicase gene (Donaldson et al. 2007).

The recently established method for purification of entire functional (membranebound) RTCs (van Hemert et al. 2008) presents exciting new possibilities to study coronavirus RNA synthesis. Advanced imaging techniques including cryo-electron microscopy have provided fascinating new insight into key structures involved in virus replication. For example, cryo-electron microscopy of ribosomes stalled at a specific stage of frameshifting provided a glimpse of how the structure of the mRNA template affects ribosome function to mediate this frameshift (Namy et al. 2006), and electron tomography of SARS-CoV-infected cells provided a 3D view of the unique continuous reticulovesicular network, the formation of which is induced by the virus (Knoops et al. 2008). However, much remains to be studied to understand how the virus coaxes the cell to produce these structures. The precise role of these membrane structures in virus replication and, possibly, immune evasion need to be characterized in more detail.

Further progress has been made in our understanding of the interactions of the virus with the host cell, especially with regard to innate immune responses to coronavirus infections and the role of specific viral proteins in counteracting these antiviral host responses. The understanding of these pathways in combination with biochemical, structural and genetic approaches will continue to provide exciting insights into virus replication and virus-host interactions and form the basis for the development of antiviral drugs and new and better coronavirus vaccines. 


\section{References}

Allen MD, Buckle AM, Cordell SC, Lowe J, Bycroft M (2003) The crystal structure of AF1521 a protein from Archaeoglobus fulgidus with homology to the non-histone domain of macroH2A. J Mol Biol 330:503-511

Almazan F, Galan C, Enjuanes L (2004) The nucleoprotein is required for efficient coronavirus genome replication. J Virol 78:12683-12688

Almazan F, Dediego ML, Galan C, Escors D, Alvarez E, Ortego J, Sola I, Zuniga S, Alonso S, Moreno JL, Nogales A, Capiscol C, Enjuanes L (2006) Construction of a severe acute respiratory syndrome coronavirus infectious cDNA clone and a replicon to study coronavirus RNA synthesis. J Virol 80:10900-10906

Almeida MS, Johnson MA, Herrmann T, Geralt M, Wuthrich K (2007) Novel beta-barrel fold in the NMR Structure of the replicase nonstructural protein 1 from the SARS coronavirus. J Virol $81: 3151-3161$

Anand K, Palm GJ, Mesters JR, Siddell SG, Ziebuhr J, Hilgenfeld R (2002) Structure of coronavirus main proteinase reveals combination of a chymotrypsin fold with an extra alpha-helical domain. EMBO J 21:3213-3224

Anand K, Ziebuhr J, Wadhwani P, Mesters JR, Hilgenfeld R (2003) Coronavirus main proteinase $\left(3 \mathrm{CL}^{\text {pro }}\right.$ ) structure: basis for design of anti-SARS drugs. Science 300:1763-1767

Barretto N, Jukneliene D, Ratia K, Chen Z, Mesecar AD, Baker SC (2005) The papain-like protease of severe acute respiratory syndrome coronavirus has deubiquitinating activity. J Virol 79:15189-15198

Beese LS, Steitz TA (1991) Structural basis for the $3^{\prime}-5^{\prime}$ exonuclease activity of Escherichia coli DNA polymerase I: a two metal ion mechanism. EMBO J 10:25-33

Bhardwaj K, Guarino L, Kao CC (2004) The severe acute respiratory syndrome coronavirus Nsp15 protein is an endoribonuclease that prefers manganese as a cofactor. J Virol 78:12218-12224

Bhardwaj K, Sun J, Holzenburg A, Guarino LA, Kao CC (2006) RNA recognition and cleavage by the SARS coronavirus endoribonuclease. J Mol Biol 361:243-256

Brierley I (1995) Ribosomal frameshifting viral RNAs. J Gen Virol 76:1885-1892

Brockway SM, Denison MR (2005) Mutagenesis of the murine hepatitis virus nsp1-coding region identifies residues important for protein processing, viral RNA synthesis, and viral replication. Virology 340:209-223

Brockway SM, Lu XT, Peters TR, Dermody TS, Denison MR (2004) Intracellular localization and protein interactions of the gene 1 protein $\mathrm{p} 28$ during mouse hepatitis virus replication. J Virol 78:11551-11562

Cao J, Wu CC, Lin TL (2008) Turkey coronavirus non-structure protein NSP15-an endoribonuclease. Intervirology 51:342-351

Chatterjee A, Johnson MA, Serrano P, Pedrini B, Joseph JS, Neuman BW, Saikatendu K, Buchmeier MJ, Kuhn P, Wuthrich K (2009) Nuclear magnetic resonance structure shows that the severe acute respiratory syndrome coronavirus-unique domain contains a macrodomain fold. J Virol 83:1823-1836

Chen P, Jiang M, Hu T, Liu Q, Chen XS, Guo D (2007a) Biochemical characterization of exoribonuclease encoded by SARS coronavirus. J Biochem Mol Biol 40:649-655

Chen Z, Wang Y, Ratia K, Mesecar AD, Wilkinson KD, Baker SC (2007b) Proteolytic processing and deubiquitinating activity of papain-like proteases of human coronavirus NL63. J Virol 81:6007-6018

Cheng A, Zhang W, Xie Y, Jiang W, Arnold E, Sarafianos SG, Ding J (2005) Expression, purification, and characterization of SARS coronavirus RNA polymerase. Virology 335:165-176

Clementz MA, Kanjanahaluethai A, O'Brien TE, Baker SC (2008) Mutation in murine coronavirus replication protein nsp4 alters assembly of double membrane vesicles. Virology 375:118-129

Connor RF, Roper RL (2007) Unique SARS-CoV protein nsp1: bioinformatics, biochemistry and potential effects on virulence. Trends Microbiol 15:51-53 
Decroly E, Imbert I, Coutard B, Bouvet M, Selisko B, Alvarez K, Gorbalenya AE, Snijder EJ, Canard B (2008) Coronavirus nonstructural protein 16 is a cap-0 binding enzyme possessing (nucleoside-2'O)-methyltransferase activity. J Virol 82:8071-8084

Deming DJ, Graham RL, Denison MR, Baric RS (2007) Processing of open reading frame 1a replicase proteins nsp7 to nsp10 in murine hepatitis virus strain A59 replication. J Virol 81:10280-10291

Devaraj SG, Wang N, Chen Z, Chen Z, Tseng M, Barretto N, Lin R, Peters CJ, Tseng CT, Baker SC, Li K (2007) Regulation of IRF-3-dependent innate immunity by the papain-like protease domain of the severe acute respiratory syndrome coronavirus. J Biol Chem 282:32208-32221

Donaldson EF, Graham RL, Sims AC, Denison MR, Baric RS (2007) Analysis of murine hepatitis virus strain A59 temperature-sensitive mutant TS-LA6 suggests that nsp10 plays a critical role in polyprotein processing. J Virol 81:7086-7098

Dong H, Ray D, Ren S, Zhang B, Puig-Basagoiti F, Takagi Y, Ho CK, Li H, Shi PY (2007) Distinct RNA elements confer specificity to flavivirus RNA cap methylation events. J Virol 81:44124421

Dong H, Ren S, Zhang B, Zhou Y, Puig-Basagoiti F, Li H, Shi PY (2008) West Nile virus methyltransferase catalyzes two methylations of the viral RNA cap through a substraterepositioning mechanism. J Virol 82:4295-4307

Dos Ramos F, Carrasco M, Doyle T, Brierley I (2004) Programmed -1 ribosomal frameshifting in the SARS coronavirus. Biochem Soc Trans 32:1081-1083

Dougherty WG, Semler BL (1993) Expression of virus-encoded proteinases: functional and structural similarities with cellular enzymes. Microbiol Rev 57:781-822

Draker R, Roper RL, Petric M, Tellier R (2006) The complete sequence of the bovine torovirus genome. Virus Res 115:56-68

Eckerle LD, Lu X, Sperry SM, Choi L, Denison MR (2007) High fidelity of murine hepatitis virus replication is decreased in nsp14 exoribonuclease mutants. J Virol 81:12135-12144

Egloff MP, Ferron F, Campanacci V, Longhi S, Rancurel C, Dutartre H, Snijder EJ, Gorbalenya AE, Cambillau C, Canard B (2004) The severe acute respiratory syndrome-coronavirus replicative protein nsp9 is a single-stranded RNA-binding subunit unique in the RNA virus world. Proc Natl Acad Sci USA 101:3792-3796

Egloff MP, Malet H, Putics A, Heinonen M, Dutartre H, Frangeul A, Gruez A, Campanacci V, Cambillau C, Ziebuhr J, Ahola T, Canard B (2006) Structural and functional basis for ADPribose and poly(ADP-ribose) binding by viral macro domains. J Virol 80:8493-8502

Eriksson KK, Cervantes-Barragan L, Ludewig B, Thiel V (2008) Mouse hepatitis virus liver pathology is dependent on ADP-ribose- $1^{\prime \prime}$-phosphatase, a viral function conserved in the alphalike supergroup. J Virol 82:12325-12334

Fan K, Wei P, Feng Q, Chen S, Huang C, Ma L, Lai B, Pei J, Liu Y, Chen J, Lai L (2004) Biosynthesis, purification, and substrate specificity of severe acute respiratory syndrome coronavirus 3C-like proteinase. J Biol Chem 279:1637-1642

Fan K, Ma L, Han X, Liang H, Wei P, Liu Y, Lai L (2005) The substrate specificity of SARS coronavirus 3C-like proteinase. Biochem Biophys Res Commun 329:934-940

Feder M, Pas J, Wyrwicz LS, Bujnicki JM (2003) Molecular phylogenetics of the RrmJ/fibrillarin superfamily of ribose 2'-O-methyltransferases. Gene 302:129-138

Gadlage MJ, Graham RL, Denison MR (2008) Murine coronaviruses encoding nsp2 at different genomic loci have altered replication, protein expression, and localization. J Virol 82: 11964-11969

Gorbalenya AE, Koonin EV, Donchenko AP, Blinov VM (1989a) Two related superfamilies of putative helicases involved in replication, recombination, repair and expression of DNA and RNA genomes. Nucleic Acids Res 17:4713-4730

Gorbalenya AE, Koonin EV, Donchenko AP, Blinov VM (1989b) Coronavirus genome: prediction of putative functional domains in the non-structural polyprotein by comparative amino acid sequence analysis. Nucleic Acids Res 17:4847-4861 
Gorbalenya AE, Koonin EV, Lai MM (1991) Putative papain-related thiol proteases of positivestrand RNA viruses. Identification of rubi- and aphthovirus proteases and delineation of a novel conserved domain associated with proteases of rubi-, alpha- and coronaviruses. FEBS Lett 288:201-205

Gorbalenya AE, Enjuanes L, Ziebuhr J, Snijder EJ (2006) Nidovirales: evolving the largest RNA virus genome. Virus Res 117:17-37

Gosert R, Kanjanahaluethai A, Egger D, Bienz K, Baker SC (2002) RNA replication of mouse hepatitis virus takes place at double-membrane vesicles. J Virol 76:3697-3708

Graham RL, Sims AC, Brockway SM, Baric RS, Denison MR (2005) The nsp2 replicase proteins of murine hepatitis virus and severe acute respiratory syndrome coronavirus are dispensable for viral replication. J Virol 79:13399-13411

Guarino LA, Bhardwaj K, Dong W, Sun J, Holzenburg A, Kao C (2005) Mutational analysis of the SARS virus Nsp15 endoribonuclease: identification of residues affecting hexamer formation. J Mol Biol 353:1106-1117

Harcourt BH, Jukneliene D, Kanjanahaluethai A, Bechill J, Severson KM, Smith CM, Rota PA, Baker SC (2004) Identification of severe acute respiratory syndrome coronavirus replicase products and characterization of papain-like protease activity. J Virol 78:13600-13612

Herold J, Siddell SG (1993) An 'elaborated' pseudoknot is required for high frequency frameshifting during translation of HCV 229E polymerase mRNA. Nucleic Acids Res 21:5838-5842

Heusipp G, Harms U, Siddell SG, Ziebuhr J (1997) Identification of an ATPase activity associated with a 71-kilodalton polypeptide encoded in gene 1 of the human coronavirus 229E. J Virol 71:5631-5634

Imbert I, Guillemot JC, Bourhis JM, Bussetta C, Coutard B, Egloff MP, Ferron F, Gorbalenya AE, Canard B (2006) A second, non-canonical RNA-dependent RNA polymerase in SARS coronavirus. EMBO J 25:4933-4942

Imbert I, Snijder EJ, Dimitrova M, Guillemot JC, Lecine P, Canard B (2008) The SARS-Coronavirus PLnc domain of $\mathrm{nsp} 3$ as a replication/transcription scaffolding protein. Virus Res 133:136-148

Ivanov KA, Ziebuhr J (2004) Human coronavirus 229E nonstructural protein 13: characterization of duplex-unwinding, nucleoside triphosphatase, and RNA $5^{\prime}$-triphosphatase activities. J Virol 78:7833-7838

Ivanov KA, Thiel V, Dobbe JC, van der Meer Y, Snijder EJ, Ziebuhr J (2004a) Multiple enzymatic activities associated with severe acute respiratory syndrome coronavirus helicase. J Virol 78:5619-5632

Ivanov KA, Hertzig T, Rozanov M, Bayer S, Thiel V, Gorbalenya AE, Ziebuhr J (2004b) Major genetic marker of nidoviruses encodes a replicative endoribonuclease. Proc Natl Acad Sci USA 101:12694-12699

Joseph JS, Saikatendu KS, Subramanian V, Neuman BW, Brooun A, Griffith M, Moy K, Yadav MK, Velasquez J, Buchmeier MJ, Stevens RC, Kuhn P (2006) Crystal structure of nonstructural protein 10 from the severe acute respiratory syndrome coronavirus reveals a novel fold with two zinc-binding motifs. J Virol 80:7894-7901

Kamitani W, Narayanan K, Huang C, Lokugamage K, Ikegami T, Ito N, Kubo H, Makino S (2006) Severe acute respiratory syndrome coronavirus nsp1 protein suppresses host gene expression by promoting host mRNA degradation. Proc Natl Acad Sci USA 103:12885-12890

Kang H, Bhardwaj K, Li Y, Palaninathan S, Sacchettini J, Guarino L, Leibowitz JL, Kao CC (2007) Biochemical and genetic analyses of murine hepatitis virus Nsp15 endoribonuclease. J Virol 81:13587-13597

Karras GI, Kustatscher G, Buhecha HR, Allen MD, Pugieux C, Sait F, Bycroft M, Ladurner AG (2005) The macro domain is an ADP-ribose binding module. EMBO J 24:1911-1920

Knoops K, Kikkert M, Worm SH, Zevenhoven-Dobbe JC, van der Meer Y, Koster AJ, Mommaas AM, Snijder EJ (2008) SARS-coronavirus replication is supported by a reticulovesicular network of modified endoplasmic reticulum. PLoS Biol 6:e226 
Koonin EV (1991) The phylogeny of RNA-dependent RNA polymerases of positive-strand RNA viruses. J Gen Virol 72:2197-2206

Lai MM, Patton CD, Stohlman SA (1982) Further characterization of mRNA's of mouse hepatitis virus: presence of common 5'-end nucleotides. J Virol 41:557-565

Laneve P, Altieri F, Fiori ME, Scaloni A, Bozzoni I, Caffarelli E (2003) Purification, cloning, and characterization of XendoU, a novel endoribonuclease involved in processing of intronencoded small nucleolar RNAs in Xenopus laevis. J Biol Chem 278:13026-13032

Langberg SR, Moss B (1981) Post-transcriptional modifications of mRNA. Purification and characterization of cap I and cap II RNA (nucleoside-2'-)-methyltransferases from HeLa cells. J Biol Chem 256:10054-10060

Lindner HA, Fotouhi-Ardakani N, Lytvyn V, Lachance P, Sulea T, Menard R (2005) The papainlike protease from the severe acute respiratory syndrome coronavirus is a deubiquitinating enzyme. J Virol 79:15199-15208

Lindner HA, Lytvyn V, Qi H, Lachance P, Ziomek E, Menard R (2007) Selectivity in ISG15 and ubiquitin recognition by the SARS coronavirus papain-like protease. Arch Biochem Biophys 466:8-14

Marra MA, Jones SJ, Astell CR, Holt RA, Brooks-Wilson A, Butterfield YS, Khattra J, Asano JK, Barber SA, Chan SY, Cloutier A, Coughlin SM, Freeman D, Girn N, Griffith OL, Leach SR, Mayo M, McDonald H, Montgomery SB, Pandoh PK, Petrescu AS, Robertson AG, Schein JE, Siddiqui A, Smailus DE, Stott JM, Yang GS, Plummer F, Andonov A, Artsob H, Bastien N, Bernard K, Booth TF, Bowness D, Czub M, Drebot M, Fernando L, Flick R, Garbutt M, Gray M, Grolla A, Jones S, Feldmann H, Meyers A, Kabani A, Li Y, Normand S, Stroher U, Tipples GA, Tyler S, Vogrig R, Ward D, Watson B, Brunham RC, Krajden M, Petric M, Skowronski DM, Upton C, Roper RL (2003) The Genome sequence of the SARS-associated coronavirus. Science 300:1399-1404

Masters PS (2006) The molecular biology of coronaviruses. Adv Virus Res 66:193-292

Miknis ZJ, Donaldson EF, Umland TC, Rimmer RA, Baric RS, Schultz LW (2009) SARS-CoV nsp9 dimerization is essential for efficient viral growth. J Virol Jan 19 (Epub ahead of print)

Minskaia E, Hertzig T, Gorbalenya AE, Campanacci V, Cambillau C, Canard B, Ziebuhr J (2006) Discovery of an RNA virus $3^{\prime}->5^{\prime}$ exoribonuclease that is critically involved in coronavirus RNA synthesis. Proc Natl Acad Sci USA 103:5108-5113

Namy O, Moran SJ, Stuart DI, Gilbert RJ, Brierley I (2006) A mechanical explanation of RNA pseudoknot function in programmed ribosomal frameshifting. Nature 441:244-247

Narayanan K, Huang C, Lokugamage K, Kamitani W, Ikegami T, Tseng CT, Makino S (2008) Severe acute respiratory syndrome coronavirus nsp1 suppresses host gene expression, including that of type I interferon, in infected cells. J Virol 82:4471-4479

Neuman BW, Joseph JS, Saikatendu KS, Serrano P, Chatterjee A, Johnson MA, Liao L, Klaus JP, Yates JR 3 rd, Wuthrich K, Stevens RC, Buchmeier MJ, Kuhn P (2008) Proteomics analysis unravels the functional repertoire of coronavirus nonstructural protein 3. J Virol 82:5279-5294

Neuvonen M, Ahola T (2009) Differential activities of cellular and viral macro domain proteins in binding of ADP-ribose metabolites. J Mol Biol 385:212-225

Oostra M, te Lintelo EG, Deijs M, Verheije MH, Rottier PJ, de Haan CA (2007) Localization and membrane topology of coronavirus nonstructural protein 4: involvement of the early secretory pathway in replication. J Virol 81:12323-12336

Oostra M, Hagemeijer MC, van Gent M, Bekker CP, te Lintelo EG, Rottier PJ, De Haan CA (2008) Topology and membrane anchoring of the coronavirus replication complex: not all hydrophobic domains of nsp3 and nsp6 are membrane spanning. J Virol 82:12392-12405

Palmenberg AC (1990) Proteolytic processing of picornaviral polyprotein. Annu Rev Microbiol 44:603-623

Pasternak AO, Spaan WJM, Snijder EJ (2006) Nidovirus transcription: how to make sense...? J Gen Virol 87:1403-1421 
Plotch SJ, Bouloy M, Ulmanen I, Krug RM (1981) A unique cap(m7G pppXm)-dependent influenza virion endonuclease cleaves capped RNAs to generate the primers that initiate viral RNA transcription. Cell 23:847-858

Prentice E, McAuliffe J, Lu X, Subbarao K, Denison MR (2004) Identification and characterization of severe acute respiratory syndrome coronavirus replicase proteins. J Virol 78:9977-9986

Putics A, Filipowicz W, Hall J, Gorbalenya AE, Ziebuhr J (2005) ADP-ribose-1"-monophosphatase: a conserved coronavirus enzyme that is dispensable for viral replication in tissue culture. J Virol 79:12721-12731

Putics A, Gorbalenya AE, Ziebuhr J (2006) Identification of protease and ADP-ribose 1"-monophosphatase activities associated with transmissible gastroenteritis virus non-structural protein 3 . J Gen Virol 87:651-656

Ratia K, Saikatendu KS, Santarsiero BD, Barretto N, Baker SC, Stevens RC, Mesecar AD (2006) Severe acute respiratory syndrome coronavirus papain-like protease: structure of a viral deubiquitinating enzyme. Proc Natl Acad Sci USA 103:5717-5722

Ray D, Shah A, Tilgner M, Guo Y, Zhao Y, Dong H, Deas TS, Zhou Y, Li H, Shi PY (2006) West Nile virus $5^{\prime}$-cap structure is formed by sequential guanine N-7 and ribose 2'-O methylations by nonstructural protein 5. J Virol 80:8362-8370

Ricagno S, Egloff MP, Ulferts R, Coutard B, Nurizzo D, Campanacci V, Cambillau C, Ziebuhr J, Canard B (2006) Crystal structure and mechanistic determinants of SARS coronavirus nonstructural protein 15 define an endoribonuclease family. Proc Natl Acad Sci USA 103:1189211897

Rota PA, Oberste MS, Monroe SS, Nix WA, Campagnoli R, Icenogle JP, Penaranda S, Bankamp B, Maher K, Chen MH, Tong S, Tamin A, Lowe L, Frace M, DeRisi JL, Chen Q, Wang D, Erdman DD, Peret TC, Burns C, Ksiazek TG, Rollin PE, Sanchez A, Liffick S, Holloway B, Limor J, McCaustland K, Olsen-Rasmussen M, Fouchier R, Gunther S, Osterhaus AD, Drosten C, Pallansch MA, Anderson LJ, Bellini WJ (2003) Characterization of a novel coronavirus associated with severe acute respiratory syndrome. Science 300:1394-1399

Saikatendu KS, Joseph JS, Subramanian V, Clayton T, Griffith M, Moy K, Velasquez J, Neuman BW, Buchmeier MJ, Stevens RC, Kuhn P (2005) Structural basis of severe acute respiratory syndrome coronavirus ADP-ribose-1"-phosphate dephosphorylation by a conserved domain of nsP3. Structure 13:1665-1675

Salonen A, Ahola T, Kaariainen L (2005) Viral RNA replication in association with cellular membranes. Curr Top Microbiol Immunol 285:139-173

Sawicki SG, Sawicki DL (1986) Coronavirus minus-strand RNA synthesis and effect of cycloheximide on coronavirus RNA synthesis. J Virol 57:328-334

Sawicki SG, Sawicki DL, Siddell SG (2007) A contemporary view of coronavirus transcription. J Virol 81:20-29

Schelle B, Karl N, Ludewig B, Siddell SG, Thiel V (2005) Selective replication of coronavirus genomes that express nucleocapsid protein. J Virol 79:6620-6630

Schiller JJ, Kanjanahaluethai A, Baker SC (1998) Processing of the coronavirus MHV-JHM polymerase polyprotein: identification of precursors and proteolytic products spanning 400 kilodaltons of ORF1a. Virology 242:288-302

Schütze H, Ulferts R, Schelle B, Bayer S, Granzow H, Hoffmann B, Mettenleiter TC, Ziebuhr J (2006) Characterization of White bream virus reveals a novel genetic cluster of nidoviruses. J Virol 80:11598-11609

Serrano P, Johnson MA, Almeida MS, Horst R, Herrmann T, Joseph JS, Neuman BW, Subramanian V, Saikatendu KS, Buchmeier MJ, Stevens RC, Kuhn P, Wuthrich K (2007) Nuclear magnetic resonance structure of the N-terminal domain of nonstructural protein 3 from the severe acute respiratory syndrome coronavirus. J Virol 81:12049-12060

Seybert A, Hegyi A, Siddell SG, Ziebuhr J (2000) The human coronavirus 229E superfamily 1 helicase has RNA and DNA duplex-unwinding activities with $5^{\prime}$-to-3' polarity. RNA 6:1056-1068 
Seybert A, Posthuma CC, van Dinten LC, Snijder EJ, Gorbalenya AE, Ziebuhr J (2005) A complex zinc finger controls the enzymatic activities of nidovirus helicases. J Virol 79:696-704

Shi ST, Lai MM (2005) Viral and cellular proteins involved in coronavirus replication. Curr Top Microbiol Immunol 287:95-131

Shuman S (2001) Structure, mechanism, and evolution of the mRNA capping apparatus. Prog Nucleic Acid Res Mol Biol 66:1-40

Snijder EJ, van Tol H, Roos N, Pedersen KW (2001) Non-structural proteins 2 and 3 interact to modify host cell membranes during the formation of the arterivirus replication complex. J Gen Virol 82:985-994

Snijder EJ, Bredenbeek PJ, Dobbe JC, Thiel V, Ziebuhr J, Poon LL, Guan Y, Rozanov M, Spaan WJ, Gorbalenya AE (2003) Unique and conserved features of genome and proteome of SARScoronavirus, an early split-off from the coronavirus group 2 lineage. J Mol Biol 331:991-1004

Spaan W, Delius H, Skinner M, Armstrong J, Rottier P, Smeekens S, van der Zeijst BA, Siddell SG (1983) Coronavirus mRNA synthesis involves fusion of non-contiguous sequences. EMBO J 2:1839-1844

Sparks JS, Lu X, Denison MR (2007) Genetic analysis of Murine hepatitis virus nsp4 in virus replication. J Virol 81:12554-12563

Su D, Lou Z, Sun F, Zhai Y, Yang H, Zhang R, Joachimiak A, Zhang XC, Bartlam M, Rao Z (2006) Dodecamer structure of severe acute respiratory syndrome coronavirus nonstructural protein nsp10. J Virol 80:7902-7908

Sulea T, Lindner HA, Purisima EO, Menard R (2005) Deubiquitination, a new function of the severe acute respiratory syndrome coronavirus papain-like protease? J Virol 79:4550-4551

Sutton G, Fry E, Carter L, Sainsbury S, Walter T, Nettleship J, Berrow N, Owens R, Gilbert R, Davidson A, Siddell S, Poon LL, Diprose J, Alderton D, Walsh M, Grimes JM, Stuart DI (2004) The nsp9 replicase protein of SARS-coronavirus, structure and functional insights. Structure 12:341-353

Tan J, Verschueren KH, Anand K, Shen J, Yang M, Xu Y, Rao Z, Bigalke J, Heisen B, Mesters JR, Chen K, Shen X, Jiang H, Hilgenfeld R (2005) pH-dependent conformational flexibility of the SARS-CoV main proteinase (M(pro)) dimer: molecular dynamics simulations and multiple X-ray structure analyses. J Mol Biol 354:25-40

Tan J, Kusov Y, Mutschall D, Tech S, Nagarajan K, Hilgenfeld R, Schmidt CL (2007) The "SARS-unique domain" (SUD) of SARS coronavirus is an oligo(G)-binding protein. Biochem Biophys Res Commun 364:877-882

Tanner JA, Watt RM, Chai YB, Lu LY, Lin MC, Peiris JS, Poon LL, Kung HF, Huang JD (2003) The severe acute respiratory syndrome (SARS) coronavirus NTPase/helicase belongs to a distinct class of $5^{\prime}$ to $3^{\prime}$ viral helicases. J Biol Chem 278:39578-39582

Thiel V, Ivanov KA, Putics A, Hertzig T, Schelle B, Bayer S, Weissbrich B, Snijder EJ, Rabenau H, Doerr HW, Gorbalenya AE, Ziebuhr J (2003) Mechanisms and enzymes involved in SARS coronavirus genome expression. J Gen Virol 84:2305-2315

van Dinten LC, van Tol H, Gorbalenya AE, Snijder EJ (2000) The predicted metal-binding region of the arterivirus helicase protein is involved in subgenomic mRNA synthesis, genome replication, and virion biogenesis. J Virol 74:5213-5223

van Hemert MJ, van den Worm SH, Knoops K, Mommaas AM, Gorbalenya AE, Snijder EJ (2008) SARS-coronavirus replication/transcription complexes are membrane-protected and need a host factor for activity in vitro. PLoS Pathog 4:e1000054

Wathelet MG, Orr M, Frieman MB, Baric RS (2007) Severe acute respiratory syndrome coronavirus evades antiviral signaling: role of nsp1 and rational design of an attenuated strain. J Virol $81: 11620-11633$

Xu X, Liu Y, Weiss S, Arnold E, Sarafianos SG, Ding J (2003) Molecular model of SARS coronavirus polymerase: implications for biochemical functions and drug design. Nucleic Acids Res 31:7117-7130 
Xu X, Zhai Y, Sun F, Lou Z, Su D, Xu Y, Zhang R, Joachimiak A, Zhang XC, Bartlam M, Rao Z (2006) New antiviral target revealed by the hexameric structure of mouse hepatitis virus nonstructural protein nsp15. J Virol 80:7909-7917

Xu Y, Cong L, Chen C, Wei L, Zhao Q, Xu X, Ma Y, Bartlam M, Rao Z (2009) Crystal structures of two coronavirus ADP-ribose-1" ${ }^{\prime \prime}$-monophosphatases and their complexes with ADP-Ribose: a systematic structural analysis of the viral ADRP domain. J Virol 83:1083-1092

Xue X, Yu H, Yang H, Xue F, Wu Z, Shen W, Li J, Zhou Z, Ding Y, Zhao Q, Zhang XC, Liao M, Bartlam M, Rao Z (2008) Structures of two coronavirus main proteases: implications for substrate binding and antiviral drug design. J Virol 82:2515-2527

Yang H, Yang M, Ding Y, Liu Y, Lou Z, Zhou Z, Sun L, Mo L, Ye S, Pang H, Gao GF, Anand K, Bartlam M, Hilgenfeld R, Rao Z (2003) The crystal structures of severe acute respiratory syndrome virus main protease and its complex with an inhibitor. Proc Natl Acad Sci USA 100:13190-13195

Yang H, Xie W, Xue X, Yang K, Ma J, Liang W, Zhao Q, Zhou Z, Pei D, Ziebuhr J, Hilgenfeld R, Yuen KY, Wong L, Gao G, Chen S, Chen Z, Ma D, Bartlam M, Rao Z (2005) Design of widespectrum inhibitors targeting coronavirus main proteases. PLoS Biol 3:e324

Zhai Y, Sun F, Li X, Pang H, Xu X, Bartlam M, Rao Z (2005) Insights into SARS-CoV transcription and replication from the structure of the nsp7-nsp8 hexadecamer. Nat Struct Mol Biol 12:980-986

Zhao Q, Li S, Xue F, Zou Y, Chen C, Bartlam M, Rao Z (2008) Structure of the main protease from a global infectious human coronavirus, HCoV-HKU1. J Virol 82:8647-8655

Zheng D, Chen G, Guo B, Cheng G, Tang H (2008) PLP2, a potent deubiquitinase from murine hepatitis virus, strongly inhibits cellular type I interferon production. Cell Res 18:1105-1113

Ziebuhr J (2005) The coronavirus replicase. Curr Top Microbiol Immunol 287:57-94

Ziebuhr J (2008) Coronavirus replicative proteins. In: Perlman S, Gallagher T, Snijder EJ (eds) Nidoviruses. ASM, Washington, DC, pp 65-81

Ziebuhr J, Snijder EJ (2007) The coronavirus replicase gene: special enzymes for special viruses. In: Thiel V (ed) Coronaviruses - molecular and cellular biology. Caister Academic, Norfolk, UK, pp 33-63

Ziebuhr J, Herold J, Siddell SG (1995) Characterization of a human coronavirus (strain 229E) 3C-like proteinase activity. J Virol 69:4331-4338

Ziebuhr J, Snijder EJ, Gorbalenya AE (2000) Virus-encoded proteinases and proteolytic processing in the Nidovirales. J Gen Virol 81:853-879

Ziebuhr J, Thiel V, Gorbalenya AE (2001) The autocatalytic release of a putative RNA virus transcription factor from its polyprotein precursor involves two paralogous papain-like proteases that cleave the same peptide bond. J Biol Chem 276:33220-33232

Zuo Y, Deutscher MP (2001) Exoribonuclease superfamilies: structural analysis and phylogenetic distribution. Nucleic Acids Res 29:1017-1026

Züst R, Cervantes-Barragan L, Kuri T, Blakqori G, Weber F, Ludewig B, Thiel V (2007) Coronavirus non-structural protein 1 is a major pathogenicity factor: implications for the rational design of coronavirus vaccines. PLoS Pathog 3:e109 